\title{
Study on insulation and stresses of TBCs on a turbine vane under ununiform temperature field
}

\author{
Jianhua Liu ${ }^{1, a}$, Yongbao Liu ${ }^{1, ~ b, ~ * ~}$, Li Liu 2, c \\ ${ }^{1}$ College of Power Engineering, Naval University of Engineering, Wuhan 430033, China; \\ ${ }^{2}$ College of Physics Science and Engineering Technology, Yichun University, Yichun 336000, \\ China. \\ aljh363418@sina.cn, byongbaoliu@aliyun.com, c||4246@126.com
}

Keywords: thermal barrier coatings, insulation, stresses, turbine vane, ununiform temperature field.

\begin{abstract}
The paper focuses on insulation and stress of TBCs on a multilayer-coated blade considering ununiform temperature field. First the ununiform temperature field of TBCs was conducted by thermal-flow couple method. Then the thermal cycle residual stresses were modeled by holding the uniform temperature in the dwell step. It is found that the blade benefited more in substrate average temperature than the maximum temperature with top coating (TC) thickening, but the thickness of TC can only slightly affect the temperature fluctuation on TBCs surface. However, thickening TC produced higher normal stresses near the interface around the blade. It suggests that TBCs may suffers delamination near the interface due to residual stresses with TC thickening.
\end{abstract}

\section{Introduction}

Thermal barrier coatings (TBCs) have been widely used to protect the hot components of the gas turbine $[1,2]$. It normally has four layers including top coating (TC), thermal grown oxide (TGO), bond coating (BC), and substrate (SUB). Differences of material properties, TGO growing at elevated temperature, and harsh environment in serving, are considered as the main reasons for residual stresses and failure [3-6].Numerical method has been utilized frequently to discuss TBCs stresses based on finite element method. Freborg et al. [7] examined the stresses induced by BC oxidation. Hsueh and Fuller [8] investigated the interfacial asperity effects on residual stresses. Ranjbar-far et al. [9, 10] developed a model considering the non-homogeneous temperature to assess the stresses and failure. Further, Ranjbar-far et al. [11, 12] and Bäker and Rösler [13, 14] used debond technology to simulate the interfacial crack behavior. Bialas et al. [15], Yang et al. [16] and Zhu et al. [17] used cohesive model zone at the interface to model delamination of TBCs.

However, the computational models of previous literatures based on periodic unit can't cover the whole blade geometry and the corresponding working conditions. Our objective is to build a cascade computational model with multilayered blade. Then the ununiform temperature field was modelled by thermal-flow couple. Finally, the temperature results are used as the holding temperature field in dwell step of the thermal cycle, and the residual stresses are simulated by finite element method.

\section{Model and method}

Aerodynamic cascade flow model and the stator blade originated from Hylton et al. [18]. The blade has a constant cross section and ten coolant passages (marked with Arabic numerial 1-10 in Fig. 1). In the paper, three layers (TC, TGO, BC) were divided from the outer surface. The thickness of $\mathrm{BC}$ and TGO are $150 \mu \mathrm{m}$ and $10 \mu \mathrm{m}$, respectively. The thickness of TC $\left(\mathrm{h}_{\mathrm{TC}}\right)$ varies from $100 \mu \mathrm{m}$ to 300 $\mu \mathrm{m}$. The aerodynamic boundary conditions were kept consistent with the experiment (run number 42) [18]; the boundaries of inner coolant passages were listed in [19]. But for exploring the coatings behavior of the blade that enduring elevated temperature, the main flow inlet temperature $\left(\mathrm{T}_{\text {in }}\right)$ was modified to $1300{ }^{\circ} \mathrm{C}$. Adopt ideal gas assumption and mesh the fluid and solid domain in a uniform frame, keeping the grids across interface node to node align, as shown in Fig 1. To resolve the viscous boundary layer, Y plus value $(\mathrm{y}+)$ of the grids adjacent to the solid wall was less than 1 . Mesh 
independence was done and a steady analysis was carried out using shear stress transport turbulence model considering boundary transition in CFX code. The conduction between hot gas and TBCs was calculated by conjugate heat transfer (CHT) method, based on the conversation of energy. The interface asperity is assumed perfect and no contact thermal resistance. The properties of the layers were temperature dependent, as listed in Table 2.

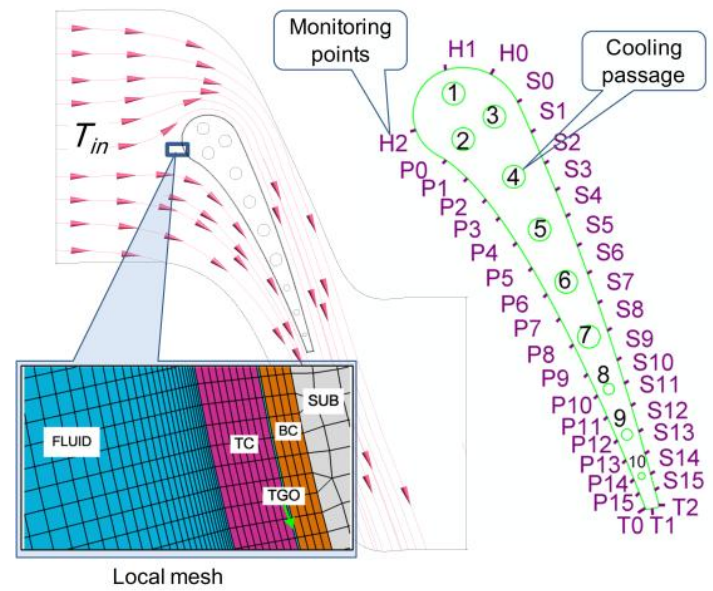

Fig. 1 The total model and local mesh

Table 1 Boundary conditions of the ten coolants [19]

\begin{tabular}{|c|c|c|}
\hline Coolant number & Constant Temperature $T\left({ }^{\circ} \mathrm{C}\right)$ & Heat transfer coefficient $h_{\text {cool }}\left(\mathrm{W} /\left(\mathrm{m}{ }^{\circ} \mathrm{C}\right)\right)$ \\
\hline 1 & 63.39 & 1943.67 \\
\hline 2 & 53.27 & 1881.45 \\
\hline 3 & 59.68 & 1893.49 \\
\hline 5 & 65.86 & 1960.62 \\
\hline 6 & 45.95 & 1850.77 \\
\hline 7 & 42.58 & 1813.36 \\
\hline 8 & 53.26 & 1871.88 \\
\hline \hline & 86.83 & 2643.07 \\
\hline 10 & 87.89 & 1809.89 \\
\hline
\end{tabular}

Table 2 Material properties [9, 10]

\begin{tabular}{|c|c|c|c|c|c|c|}
\hline Material & Temperature & $\begin{array}{c}\text { Young } \\
\text { modulus }\end{array}$ & $\begin{array}{c}\text { Possion } \\
\text { ratio }\end{array}$ & $\begin{array}{c}\text { Thermal } \\
\text { conductivity }\end{array}$ & $\begin{array}{c}\text { Specific } \\
\text { heat }\end{array}$ & Thermal expansion \\
\hline & $\mathrm{T}\left({ }^{\circ} \mathrm{C}\right)$ & $\mathrm{E}(\mathrm{GPa})$ & $\begin{array}{c}\mathrm{k}) \\
\mathrm{k}(\mathrm{W} /(\mathrm{m} \mathrm{K}))\end{array}$ & $\mathrm{C}(\mathrm{J} /(\mathrm{kg} \mathrm{K}))$ & $\alpha\left(10-6 /{ }^{\circ} \mathrm{C}\right)$ \\
\hline & 25 & 17.50 & 0.20 & 1.05 & 483 & 9.68 \\
\hline & 800 & - & & & & 9.88 \\
\hline & 1000 & 12.40 & & & & 10.34 \\
\hline TBC & 25 & 380 & 0.27 & 25.20 & 857 & 5.10 \\
\hline & 800 & 338 & & & & - \\
\hline & 1000 & 312 & & & & 9.80 \\
\hline & 25 & 183 & 0.30 & 4.30 & 501 & - \\
\hline & 400 & 152 & & 6.40 & 592 & 12.50 \\
\hline & 800 & 109 & & 10.20 & 781 & 14.30 \\
\hline & 1000 & - & & 16.10 & 764 & 16.00 \\
\hline & 25 & 211 & 0.3 & 11.56 & 582.2 & 12.6 \\
\hline & 400 & 188 & & 18.38 & & 14.00 \\
\hline & 800 & 157 & & 25.66 & & 15.40 \\
\hline & 1000 & 139 & & 29.30 & & 16.30 \\
\hline
\end{tabular}


As negligible solid deformation, sequential thermal stress couple can be done in the global model. The finite element model was corresponding to the multilayered blade. Considering constant cross section of the blade, plane strain behavior was applied at the mid-span section. The CPE4R element and Newton iterative method were used to simulations by automatic time increment. The preheated temperature was assumed to be $200{ }^{\circ} \mathrm{C}$, at which the blade was stress-free. The thermal history lasted 50 cycles. As shown in Fig. 2, one thermal cycle included three phases: first, heating from $25^{\circ} \mathrm{C}$ to the steady working state in $300 \mathrm{~s}$; second, standing the working state for $7200 \mathrm{~s}$; third, cooling to $25^{\circ} \mathrm{C}$ in $300 \mathrm{~s}$. The temperature field at the steady working state was imported from heat-flow couple. For the convenience of discussion, the local orientation systems were created. The local 1-direction and 2-direction represented the parallel and normal direction of the interface, respectively.

\section{Results and discussion}

\subsection{Temperature of TBCs}

The total insulation effects of TBCs were characterized by the SUB temperature. As shown in Fig. 2 , under serving conditions SUB experienced non-homogeneous temperature distribution in each case; the lowest temperature zone was at the head between the cooling passages 2 and 3; the highest temperature zone was at the tail; and distinctly the suction side was hotter than the pressure side. With $\mathrm{h}_{\mathrm{TC}}$ increasing, the hotter area at the head, suction side and the tail was reduced gradually. As shown in Fig.3, the average temperature of the surface increases with the $\mathrm{h}_{\mathrm{TC}}$ thickening. The temperature deviation (D) of TC surface was defined as the formula, $\left(T_{\text {sur }}-T_{\text {ave,sur }}\right) / T_{\text {ave,sur }}{ }^{*} 100 \%$, where $T_{\text {sur }}$ is the point temperature of the surface. There is an evident temperature fluctuation on TC surface in each case shown in Fig. 4. The negative value of $\mathrm{D}$ was about at the pressure side P1-P12, in where the peak value reached nearly $-30 \%$ at P8; the positive value of D was about at the whole tail and the suction side S2-S15, in where the peak value reached nearly $40 \%$ at $\mathrm{T} 1$. So it can be infer that prescribing the isothermal condition on the coatings surface in calculating stresses during thermal cycles is likely to bring error. The temperature decline $(\Delta \mathrm{T})$ from TBCs surface to the $460 \mu \mathrm{m}$ depth was shown in Fig. 5. There is a non-homogeneous distribution of $\Delta \mathrm{T}$ around the blade. $\Delta \mathrm{T}$ was higher at the suction side and the head than that at the pressure side and the tail.

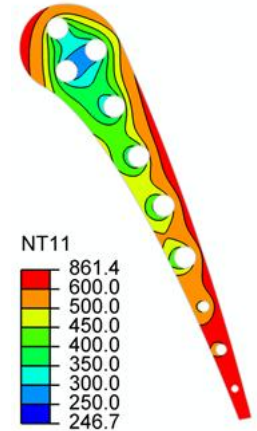

No TBC

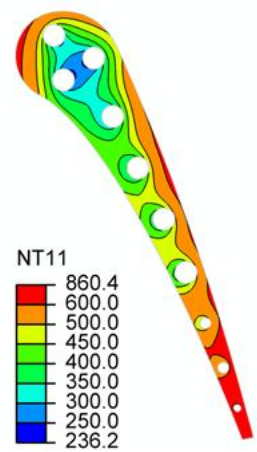

$h_{\mathrm{TC}}=100 \mu \mathrm{m}$

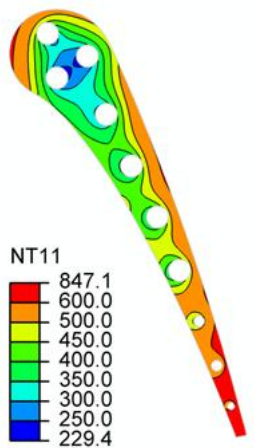

$h_{\mathrm{TC}}=200 \mu \mathrm{m}$

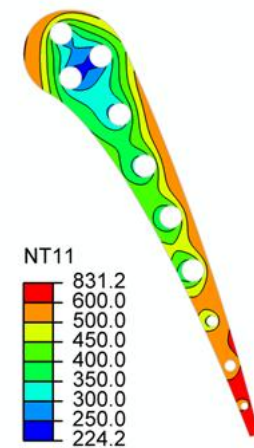

$h_{\mathrm{TC}}=300 \mu \mathrm{m}$

Fig. 2 Temperature field of the alloy

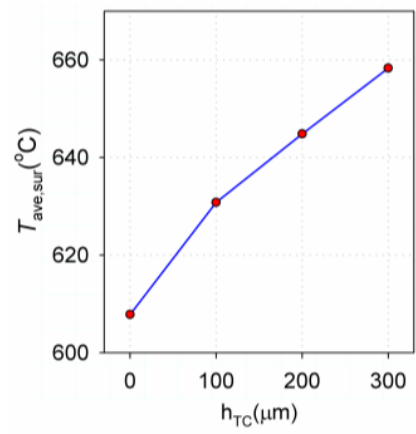

Fig. 3 Average temperature of TC surface 


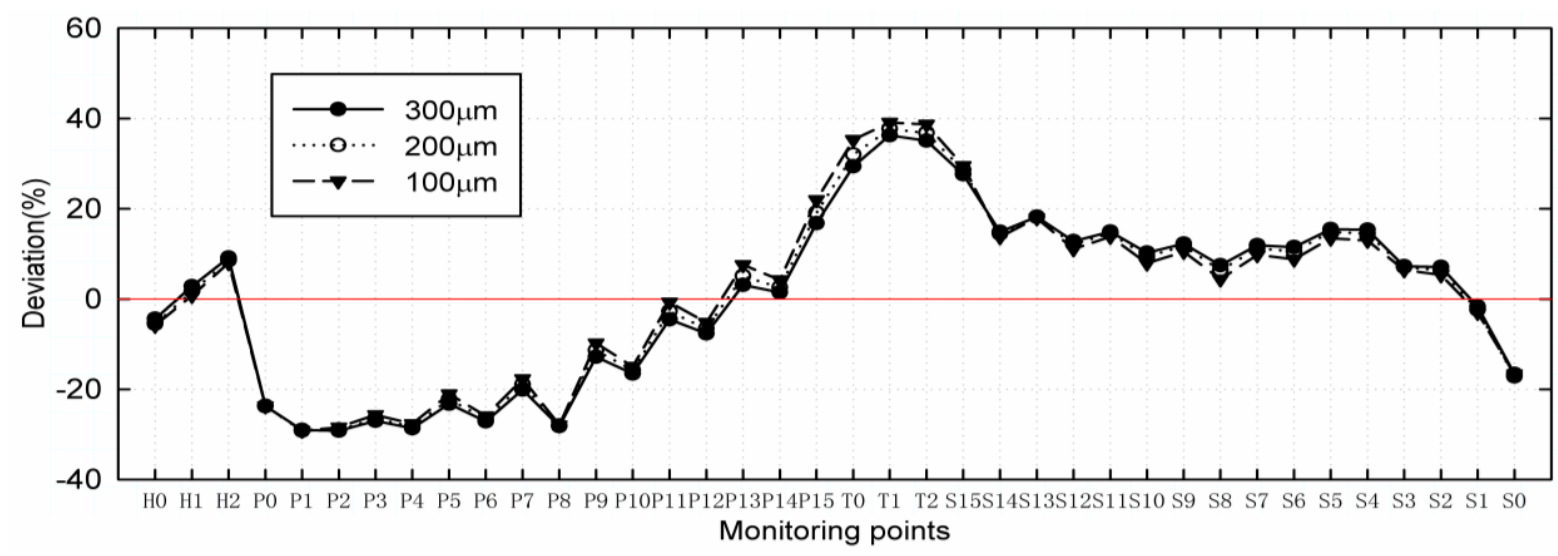

Fig. 4 Deviation of the temperature at TC surface

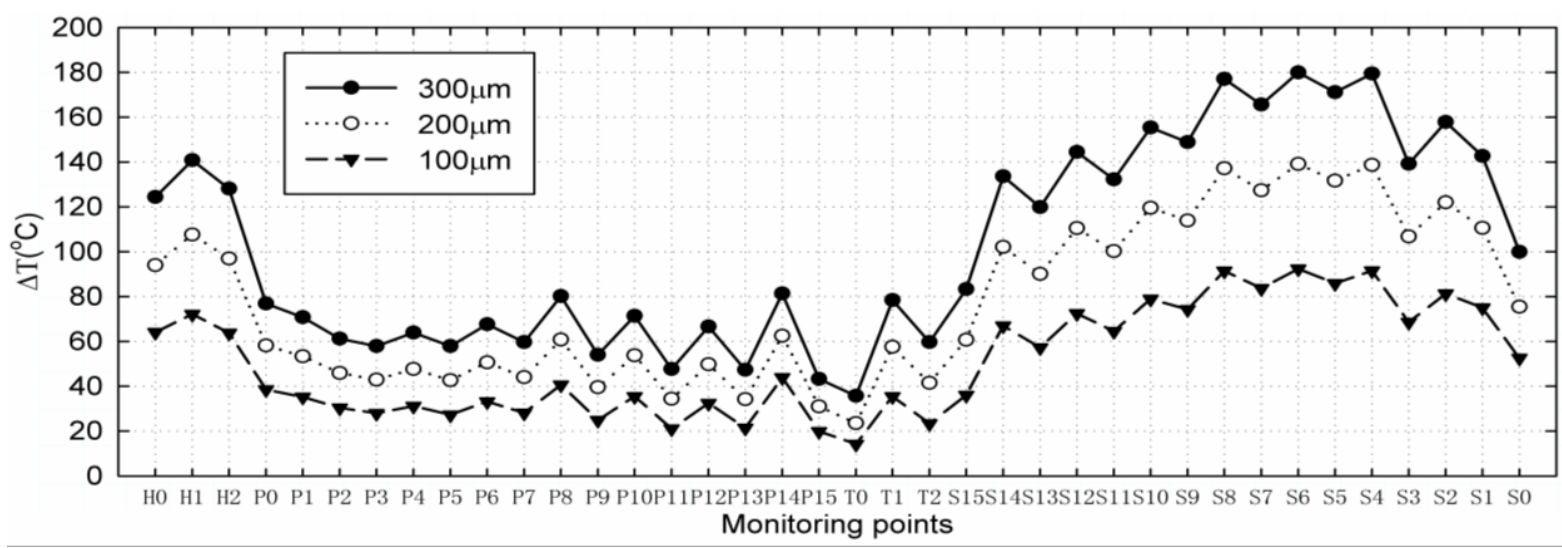

Fig. 5 The temperature decline across the thickness of TBC around the vane

As mentioned above, both the suction side and the tail are the hotter area. But we can infer that thickening TC at the suction side may gain more remarkable hot-resistant than at the tail. With $\mathrm{h}_{\mathrm{TC}}$ rising, $\Delta \mathrm{T}$ grew more at the suction side and the head than that at the pressure side and the tail. As $\mathrm{h}_{\mathrm{TC}}$ rising from 100 to $200 \mu \mathrm{m} \Delta \mathrm{T}$ added slightly more than the case rising from 200 to $300 \mu \mathrm{m}$. The maximum growth of $\Delta \mathrm{T}$ was $46.9{ }^{\circ} \mathrm{C}$ and $39.8{ }^{\circ} \mathrm{C}$ at $\mathrm{S} 6$ for the rising from 100 to $200 \mu \mathrm{m}$ and 200 to $300 \mu \mathrm{m}$, respectively. Clearly $\mathrm{h}_{\mathrm{TC}}$ exhibited notable influence on $\Delta \mathrm{T}$, but the influence is not consistent at different parts of blade.

\subsection{Average Stresses of TC}

\subsubsection{Hoop stress of $\mathrm{TC}$}

As shown in Fig. 6, hoop stress (S11) gradually grew up from the interface to the surface at the head and the tail except the case $\mathrm{h}_{\mathrm{TC}}=100 \mu \mathrm{m}$ at the tail (Fig. 6(a)). It seems no vertical crack will emerge at the tail for the compressive stresses. The potential dangerous zone was at $\mathrm{H} 0$, where S11 reached near $10.0 \mathrm{MPa}$ as $\mathrm{h}_{\mathrm{TC}}=300 \mu \mathrm{m}($ Fig. 6(c)).
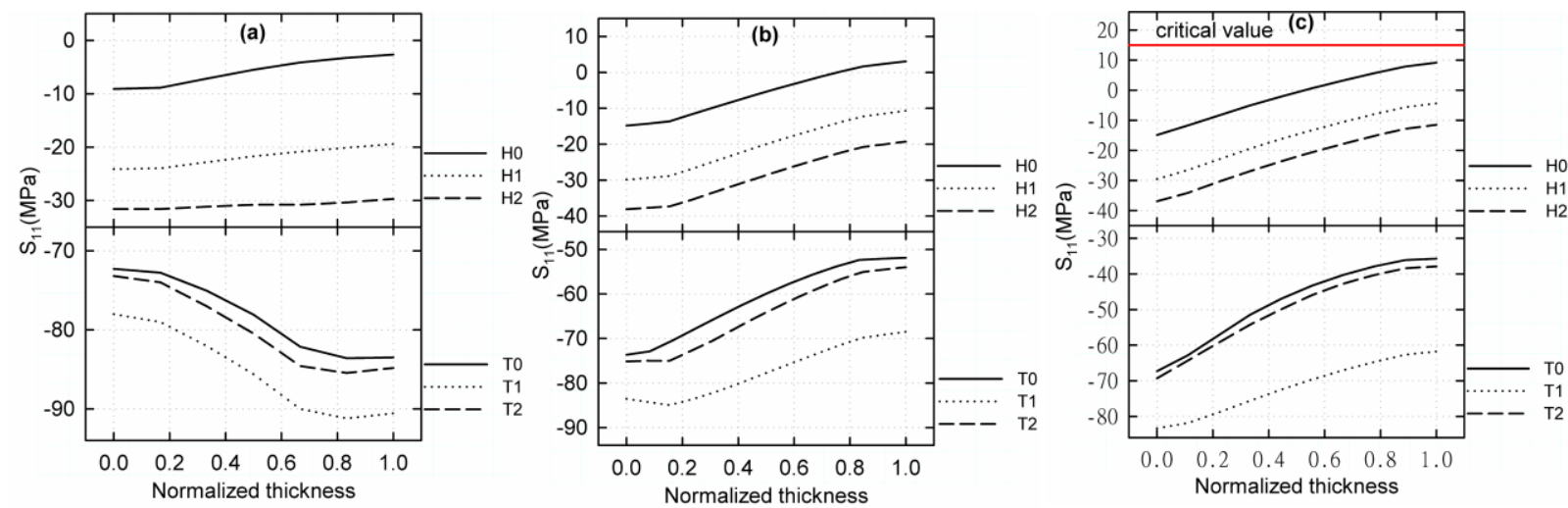

Fig. 6 Radial stress at the head and the tail of the vane: (a) $100 \mu \mathrm{m}(\mathrm{b}) 200 \mu \mathrm{m}(\mathrm{c}) 300 \mu \mathrm{m}$ 

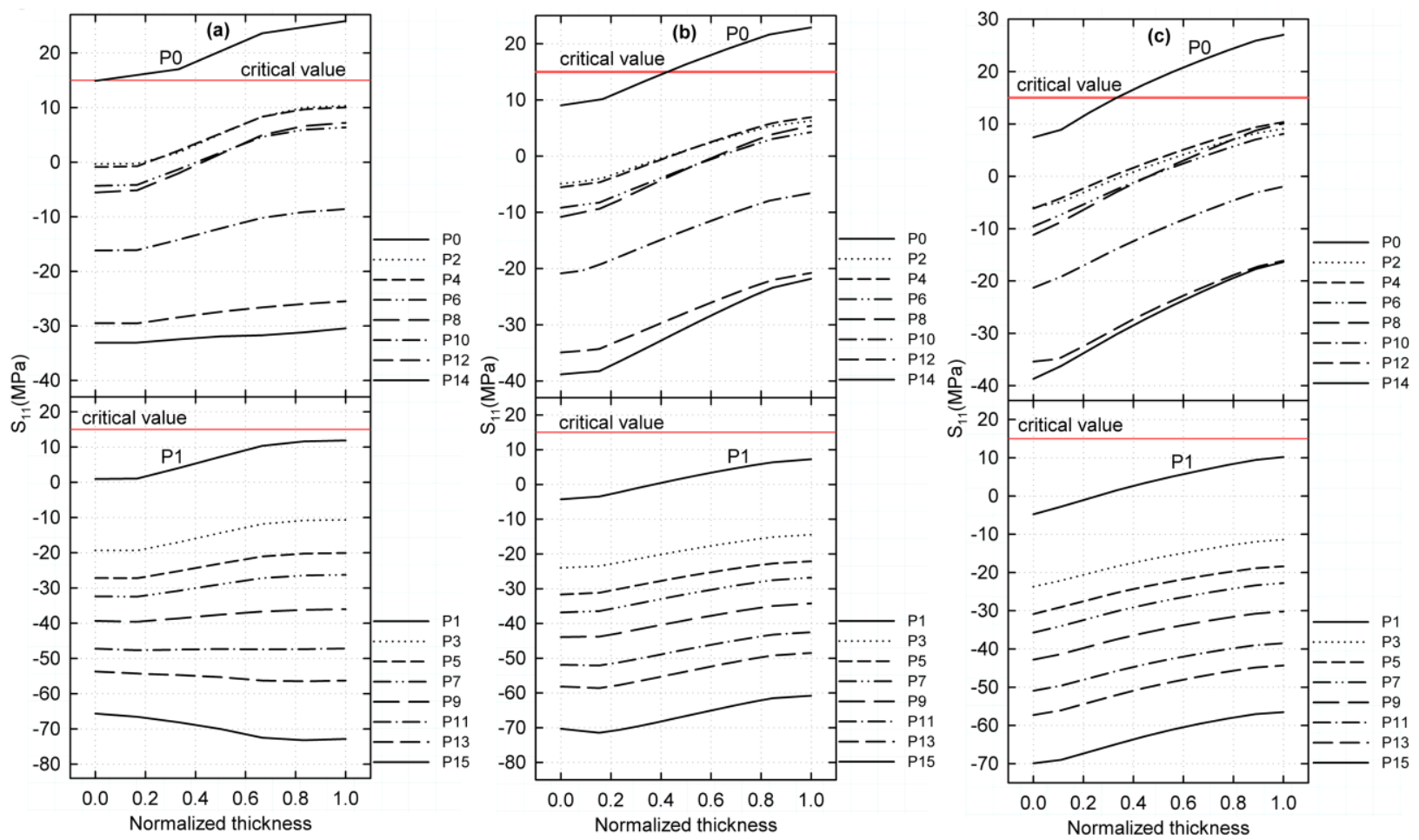

Fig. 7 Radial stress at the pressure side of the vane: (a) $100 \mu \mathrm{m}(\mathrm{b}) 200 \mu \mathrm{m}(\mathrm{c}) 300 \mu \mathrm{m}$

As shown in Fig. 7, the even point P2-P8 and the odd point P1 at the pressure side experienced tensile stresses with thickness increasing and the value of $\mathrm{S} 11$ grew close to $10 \mathrm{MPa}$ as $\mathrm{h}_{\mathrm{TC}}$ rising to $300 \mu \mathrm{m}$. These points may be the latent dangerous zones for vertical crack. However, P0 was the failure zone for vertical crack, at where S11 growing TC thickening and more than the critical stress. As shown in Fig. 8, S11 was compressive except S0 at the suction side. As TC thickening, S11 had a growth, but the value was less than the critical stress. The potential dangerous zone for vertical crack was at S0, where the value was close to the critical stress. Thus, $\mathrm{P} 0$ was the failure zone in any case; $\mathrm{H} 0, \mathrm{~S} 0, \mathrm{P} 1$, and the even points $\mathrm{P} 2-\mathrm{P} 8$ were the potential dangerous zones, at where vertical crack may be occur as further thickening of TC.
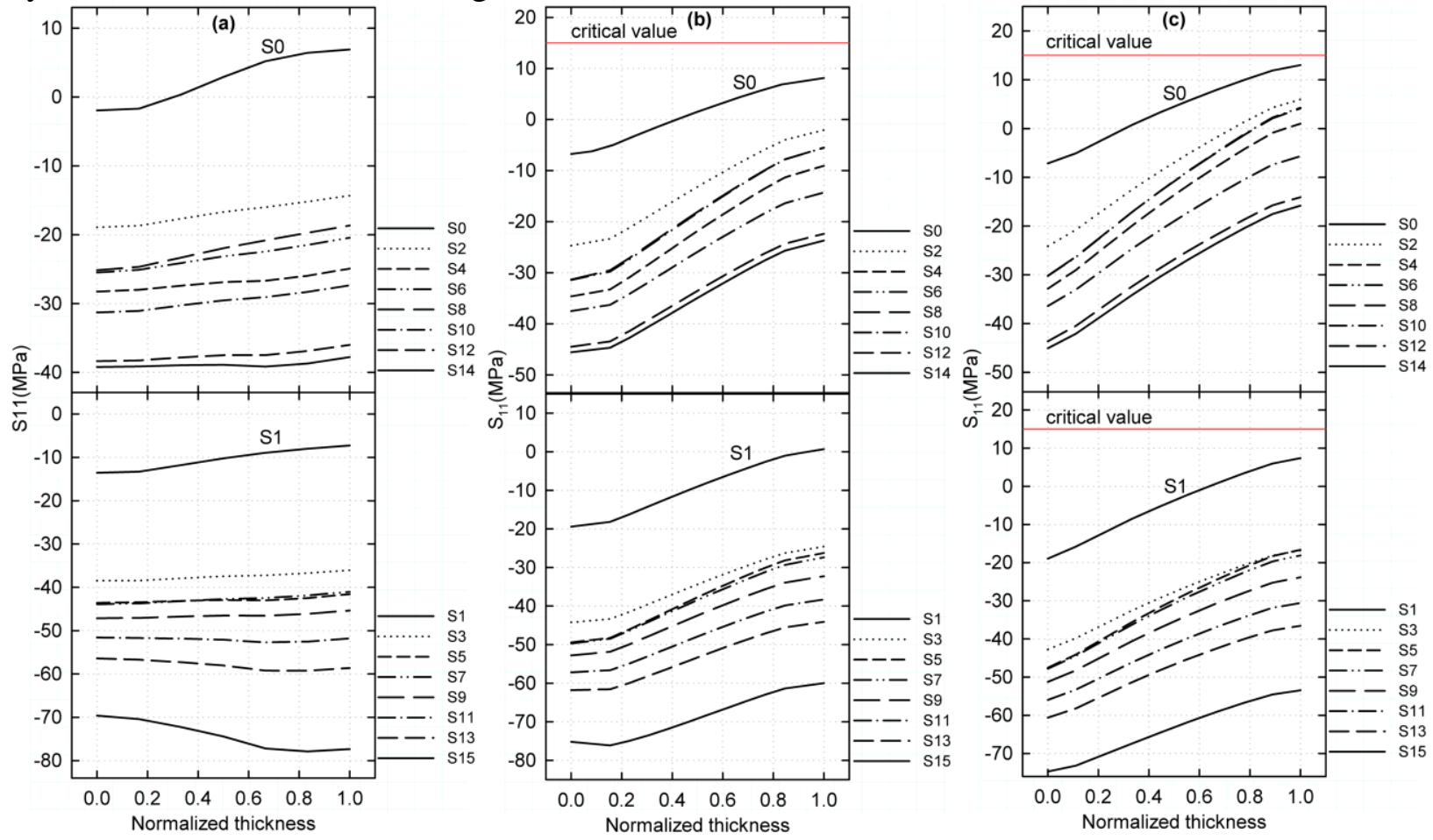

Fig. 8 Radial stress at the suction side of the vane: (a) $100 \mu \mathrm{m}$ (b) $200 \mu \mathrm{m}$ (c) $300 \mu \mathrm{m}$ 


\subsubsection{Normal stress of TC}

As $\mathrm{h}_{\mathrm{TC}}=100 \mu \mathrm{m}$ the delamination may be not happened at any part for the compressive normal stresses (S22), shown in Figs. 9(a), Figs. 10(a), and Figs. 11(a).
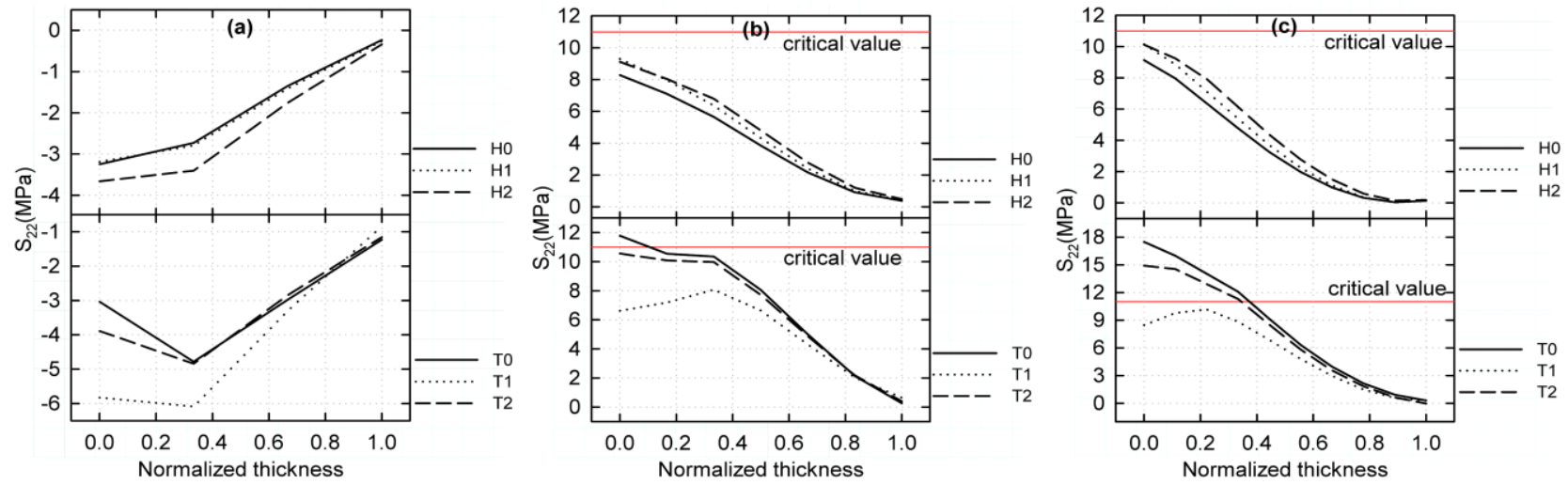

Fig. 9 Radial stress at the suction side of the vane: (a) $100 \mu \mathrm{m}(\mathrm{b}) 200 \mu \mathrm{m}(\mathrm{c}) 300 \mu \mathrm{m}$

As shown in Fig. 9, Fig. 10, and Fig. 11, as $\mathrm{h}_{\mathrm{TC}}$ rising, normal stresses near the interface converted to tensile and grew to a dangerous value that near or over the critical stress at all monitoring points; and at each monitoring point, S22 dropped down to zero from the interface to surface. It supports that the delamination may preferably occur adjacent to the interface as TC thickening. The normal stresses at the tail and head was relatively higher than that at the pressure side and suction side. The failure zone emerged at $\mathrm{T} 0$ as $\mathrm{h}_{\mathrm{TC}}=200 \mu \mathrm{m}$ (Fig. 9(b)) and at $\mathrm{T} 0$ and $\mathrm{T} 2$ as $\mathrm{h}_{\mathrm{TC}}=300 \mu \mathrm{m}$ (Fig. 9(c)). These results prove that the thickening of TC affects the normal stresses universally and indicate that the tail appear the delamination firstly. Fig. 9, Fig. 10, and Fig. 11 show that the normal stress level near the interface was higher than the hoop stress, compared to Figs. 6-Figs. 8. It implies that delamination is the main failure mode adjacent to the interface.
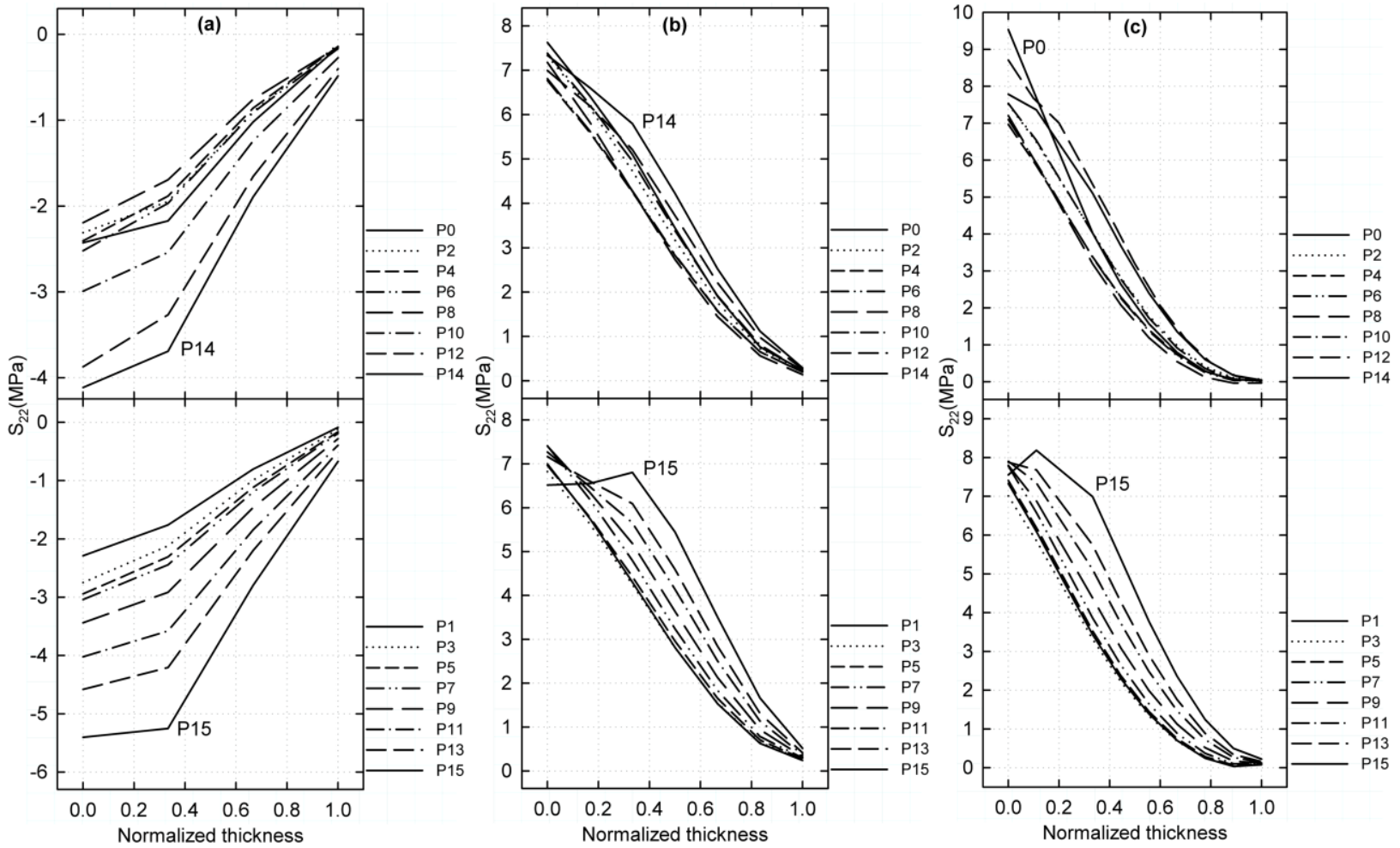

Fig. 10 Radial stress at the suction side of the vane: (a) $100 \mu \mathrm{m}(\mathrm{b}) 200 \mu \mathrm{m}(\mathrm{c}) 300 \mu \mathrm{m}$ 

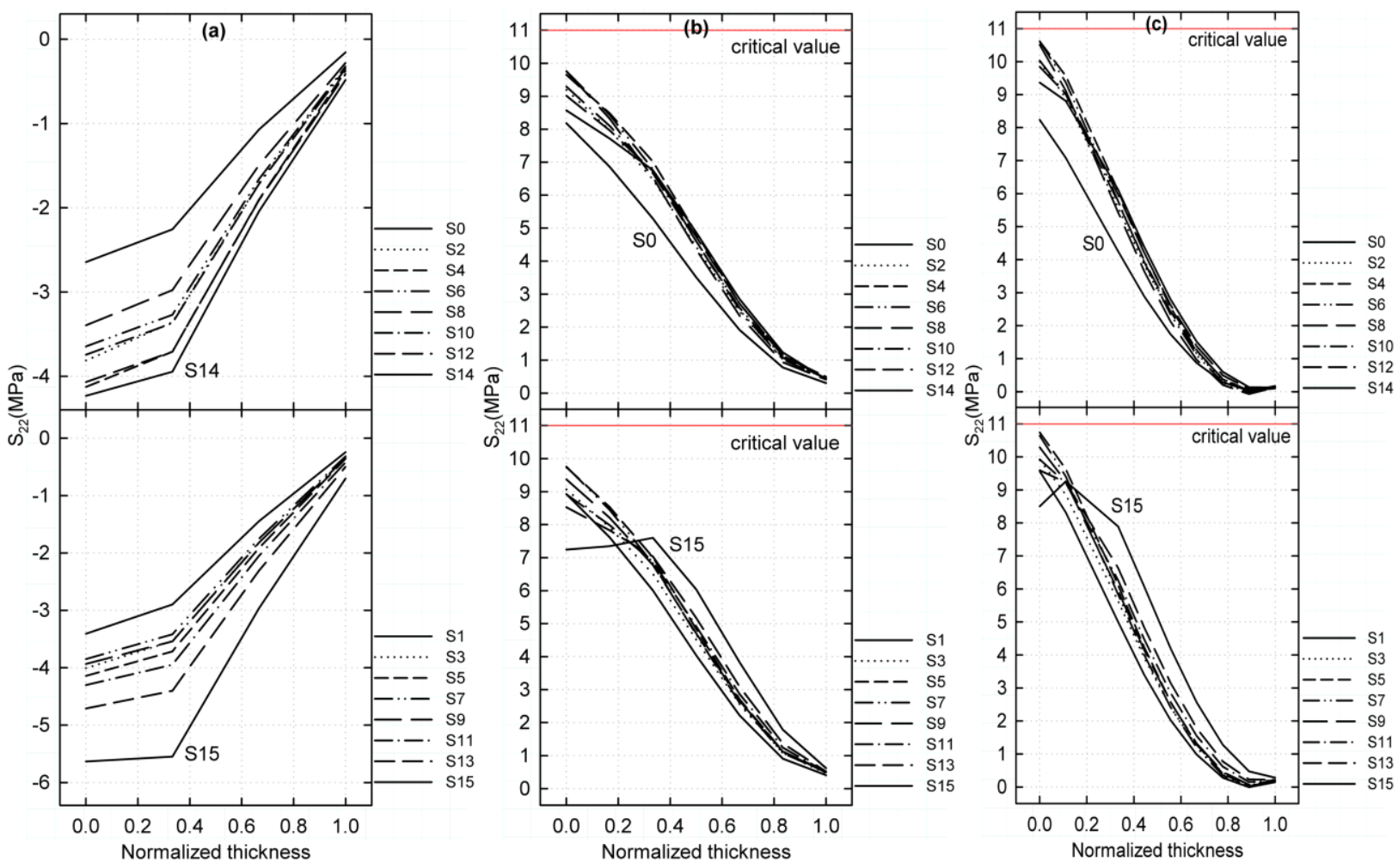

Fig. 11 Radial stress at the suction side of the vane: (a) $100 \mu \mathrm{m}(\mathrm{b}) 200 \mu \mathrm{m}(\mathrm{c}) 300 \mu \mathrm{m}$

\section{Conclusion}

The paper studies the TBCs insulation effects and residual stresses distribution, considering the working conditions of actual turbine blade. First the coupling of heat transfer and gas flow method was used for getting the actual TBCs temperature field. Then the sequential thermal stress coupling was applied for assessing the average stresses and failure zones in the global model. With $\mathrm{h}_{\mathrm{TC}}$ increasing, the hotter area was reduced gradually. A temperature fluctuation was evident on TC surface. But thickening of TC can only affect the temperature fluctuation slightly. A nonhomogeneous distribution of $\Delta \mathrm{T}$ was around the blade. The stress level near the interface of the TC/TGO is slightly growing with TC thickening around the vane. The potential failure zone for vertical crack was at P0 whether TC is thick or not; the potential dangerous zones were at $\mathrm{H} 0, \mathrm{~S} 0, \mathrm{P} 1$, and the even points P2-P8, at where vertical crack may be occur as further thickening of TC.

\section{References}

[1] A.G. Evans, D.R. Mumm, J.W. Hutchinson, G.H. Meier, F.S. Pettit, Mechanisms controlling the durability of thermal barrier coatings, Prog. Mater. Sci., 46 (2001) 505-553.

[2] N.P. Padture, M. Gell, E.H. Jordan, Thermal Barrier Coatings for Gas-Turbine Engine Applications, Science, 296 (2002) 280-284.

[3] A.G. Evans, J.W. Hutchinson, The mechanics of coating delamination in thermal gradients, Surface and Coatings Technology, 201 (2007) 7905-7916.

[4] E.P. Busso, J. Lin, S. Sakurai, A mechanistic study of oxidation-induced degradation in a plasmasprayed thermal barrier coating system.: Part II: Life prediction model, Acta Mater., 49 (2001) 1529-1536.

[5] E.P. Busso, J. Lin, S. Sakurai, M. Nakayama, A mechanistic study of oxidation-induced degradation in a plasma-sprayed thermal barrier coating system.: Part I: model formulation, Acta Mater., 49 (2001) 1515-1528.

[6] S. Widjaja, A.M. Limarga, T.H. Yip, Modeling of residual stresses in a plasma-sprayed zirconia/alumina functionally graded-thermal barrier coating, Thin Solid Films, 434 (2003) 216227. 
[7] A.M. Freborg, B.L. Ferguson, W.J. Brindley, G.J. Petrus, Modeling oxidation induced stresses in thermal barrier coatings, Mat. Sci. Eng. A-struct., 245 (1998) 182-190.

[8] C.H. Hsueh, E.R. Fuller, Residual Stresses in Thermal Barrier Coatings: Effects of Interface Asperity Curvature/Height and Oxide Thickness, Materials Science \& Engineering A, 283 (1999) 46-55.

[9] M. Ranjbar-Far, J. Absi, G. Mariaux, F. Dubois, Simulation of the effect of material properties and interface roughness on the stress distribution in thermal barrier coatings using finite element method, Mater. Design., 31 (2010) 772-781.

[10]M. Ranjbar-Far, J. Absi, G. Mariaux, S. Shahidi, Effect of Residual Stresses and Prediction of Possible Failure Mechanisms on Thermal Barrier Coating System by Finite Element Method, J. Therm. Spray. Techn., 19 (2010) 1054-1061.

[11]M. Ranjbar-Far, J. Absi, G. Mariaux, Finite Element Modeling of the Different Failure Mechanisms of a Plasma Sprayed Thermal Barrier Coatings System, J. Therm. Spray. Techn., 21 (2012) 1234-1244.

[12]M. Ranjbar-far, J. Absi, G. Mariaux, D.S. Smith, Crack propagation modeling on the interfaces of thermal barrier coating system with different thickness of the oxide layer and different interface morphologies, Mater. Design., 32 (2011) 4961-4969.

[13]M. Bäker, Finite element simulation of interface cracks in thermal barrier coatings, Comp. Mater. Sci., 64 (2012) 79-83.

[14]M. Bäker, J. Rösler, Simulation of crack propagation in thermal barrier coatings with friction, Comp. Mater. Sci., 52 (2012) 236-239.

[15]M. Białas, Finite element analysis of stress distribution in thermal barrier coatings, Surf. Coat. Tech., 202 (2008) 6002-6010.

[16]L. Yang, Q.X. Liu, Y.C. Zhou, W.G. Mao, Finite Element Simulation on Thermal Fatigue of a Turbine Blade with Thermal Barrier Coatings, J. Mater. Sci. Technol., 30 (2014) 371-380.

[17]W. Zhu, M. Cai, L. Yang, J.W. Guo, Y.C. Zhou, C. Lu, The effect of morphology of thermally grown oxide on the stress field in a turbine blade with thermal barrier coatings, Surface and Coatings Technology, 276 (2015) 160-167.

[18]L.D. Hylton, M.S. Mihelc, E.R. Turner, D.A. Nealy, R.E. York, L.D. Hylton, M.S. Mihelc, E.R. Turner, D.A. Nealy, R.E. York, Analytical and experimental evaluation of the heat transfer distribution over the surfaces of turbine vanes, AAS/Division of Dynamical Astronomy Meeting, 1983.

[19]D. Bohn, J. Ren, K. Kusterer, Cooling Performance of the Steam-Cooled Vane in a Steam Turbine Cascade, ASME Turbo Expo 2005: Power for Land, Sea, and Air, 2005, pp. 217-226. 